\title{
"Be as You Are" Clinical Research Center at the Sapienza University of Rome
}

\section{Roberto Baiocco \& Jessica Pistella}

To cite this article: Roberto Baiocco \& Jessica Pistella (2019): "Be as You Are" Clinical Research Center at the Sapienza University of Rome, Journal of Gay \& Lesbian Mental Health, DOI:

10.1080/19359705.2019.1644572

To link to this article: https://doi.org/10.1080/19359705.2019.1644572

曲 Published online: 26 Jul 2019.

Submit your article to this journal $\asymp$

View Crossmark data $־$ 


\section{"Be as You Are" Clinical Research Center at the Sapienza University of Rome}

\begin{abstract}
Italy's government has enacted few supportive policies for lesbian, gay, bisexual, transgender and all other sexual orientations and gender identities with which persons may identify (LGBTQ+), and most of the fundamental rights for sexual minorities are still not recognized. Despite this social and political situation, the Department of Developmental and Social Psychology of the Faculty of Medicine and Psychology, Sapienza University of Rome established "Be as You Are," the first Italian clinical research center specifically created for LGBTQ + people on a university campus. The facility offers several public services, such as: (a) counseling or individual psychotherapy for LGBTQ + adolescents and young adults; (b) family therapy supporting LGBTQ + adolescents; (c) parent training programs; (d) interventions in different social contexts. This letter to the editor aims to present the clinical research center and to introduce the role played by LGBTQ + health care services to improve the well-being and mental health of sexual minority individuals, especially in stigmatized contexts where sexual prejudices are still rife, such as in Italy.
\end{abstract}

\section{ARTICLE HISTORY}

Received 16 May 2019

Revised 13 June 2019

Accepted 9 July 2019

\section{KEYWORDS}

LGBTQ + clients;

psychotherapy; clinical center; research; sexual orientation

Dear Editor,

The "Be as You Are" clinical research center for the study of sexual orientation and gender identity is the first Italian public-service agency specifically created on a university campus for lesbian, gay, bisexual, transgender, and queer individuals, and those who otherwise identify as a minority in terms of sexual orientation and gender identity/expression (LGBTQ+). The center was established in 2011 by the Department of Developmental and Social Psychology of the Faculty of Medicine and Psychology, Sapienza University of Rome.

Italian society is considered one of the most conservative in the European Union. Although freedom of expression and peaceful assembly are guaranteed to sexual minority people and LGBTQ + associations, Italian people have been historically quite ambivalent regarding LGBTQ + issues. The LGBTQ + community in Italy remains a marginalized minority that faces discrimination on social, legal, and health care levels (Baiocco et al., 2014; Lingiardi et al., 2016), and this may discourage them from seeking health care services (Meyer, 2003; Naal, Abboud, \& Mahmoud, 2019).

It is well-known the Italian culture is defined by a strong Catholic influence and is bound by traditional family values. In fact, religiosity had a considerable role in the development of Italian moral, social and ethical values. Consequently, the recognition of civil rights for LGBTQ + people is progressing slowly because of the strong link between the clerical and political powers (Pacilli, Taurino, Jost, \& van der Toorn, 2011). Italy legalized same-sex civil unions in 2016, while in other Mediterranean countries with strong Catholic cultural traditions, such as Spain and Portugal, the 
recognition of civil rights for LGBTQ + people had already occurred (Ioverno et al., 2018).

In response to these challenges, the "Be as You Are" clinical research center offers the following services: (a) counseling or individual psychotherapy for sexual minority adolescents and young adults; (b) family therapy supporting LGBTQ + adolescents and their families; (c) parent training interventions aimed to promote more positive parenting skills; and (d) intervention in social contexts, such as schools, universities and sport associations. The center works with many LGBTQ + associations, such as A.ge.d.o. (the parents of LGBTQ + daughters and sons), Libellula, and Beyond Differences (both transgender associations), to provide support, facilities, counseling and psychotherapy services to their members. Since 2019, the service has collaborated with the Italian Red Cross in the "Refuge LGBTQ+" project (see: https://criroma.org/ refugelgbt), which is the first temporary shelter offering psychological counseling for LGBTQ + victims of family maltreatment and other forms of mental health support for sexual minority youth.

The "Be as You Are" clinical research center follows the "Guidelines for Psychological Practice with Lesbian, Gay, and Bisexual Clients" of the American Psychological Association (2012). These guidelines provide psychologists with a frame of reference for the treatment of sexual minority clients and basic guidelines for assessment, intervention, identity, relationship, diversity, education, training and research. In addition, the counseling service helped to write the "Italian Lesbian, Gay and Bisexual Psychotherapy Guidelines" (Lingiardi, Nardelli, \& Drescher, 2015), which has been approved by the National Council of the Italian Psychological Association (AIP), the most important association of academic psychologists in Italy.

Additionally, the center is deeply involved in training. Within the clinical and counseling profession, there is clear recognition of the need to adequately and appropriately prepare psychologists and counselors to work with LGBTQ + individuals. Given that many trainees and post-training practitioners report being ill prepared to work with sexual minority clients, the center offers training sessions and clinical supervision for mental health practitioners. The "Be as You Are" center address three fundamental issues in creating a beneficial and effective psychological and clinical practice: (1) respectful listening; (2) awareness of one's own prejudices; and (3) adequate knowledge of sexual minority lives. Due to the peculiarity of the Italian context, specific suggestions are provided for working with clients or families with strong religious affiliations.

Regarding research activities, the "Be as You Are" center promotes research programs and studies in the field of LGBTQ + well-being. In recent years, the research team published several articles in prestigious international journals regarding the following main themes: (1) mental health and minority stress (Baiocco, Pistella, Salvati, Ioverno, \& Lucidi, 2018a; Lingiardi, Baiocco, \& Nardelli, 2012); (2) homophobic bullying and adolescents adjustment (Baiocco, Pistella, Salvati, Ioverno, \& Lucidi, 2018b; Camodeca, Baiocco, \& Posa, 2018); (3) risk and protective factors associated with the coming out process (Pistella, Salvati, Ioverno, Laghi, \& Baiocco, 2016; Salvati, Pistella, Ioverno, Laghi, \& Baiocco, 2018); (4) adjustment and risk in LGBTQ + elders (Baiocco, Nardelli, Pezzuti, \& Lingiardi, 2013; Rosati, Pistella, Ioverno, \& Baiocco, 2018); and (5) well-being of children raised by same-sex parents (Baiocco, Carone, Ioverno, \& Lingiardi, 2018; Ioverno et al., 2018).

The "Be as You Are" clinical research center faced several challenges during the last 8 years. We are aware much work still remains to be done regarding the Italian 
context, but we are motivated to continue our efforts in promoting the positive identity and well-being of LGBTQ + people.

The "Be as You Are" can be accessed through this link: http://dip38.psi.uniroma1.it/ strutture/servizi-di-consulenza/6-come-sei

\section{Acknowledgments}

The authors would like to express their thanks to the staff of Department of Developmental and Social Psychology (Fabio Tufilli, Ada Florena, Marco Dessì, Elisa Marsico, Patrizia Radaelli, Lorenzo Vincenzoni, and Daniela Zaccaria) and internal collaborators (Prof. Fiorenzo Laghi, Prof. Vittorio Lingiardi, Prof. Luigi Leone, Prof. Mariella Leggio, Prof. Mauro Giacomantonio, Prof. Francesca Alby, Prof. Silvia Andreassi, and Prof. Michela di Trani), who contributed to the success of this clinical research center.

\section{Disclosure statement}

The authors have no conflicts of interest to declare.

\section{References}

American Psychological Association. (2012). Guidelines for psychological practice with lesbian, gay, and bisexual clients. American Psychologist, 67, 10-42. doi:10.1037/a0024659

Baiocco, R., Carone, N., Ioverno, S., \& Lingiardi, V. (2018). Same-sex and different-sex parent families in Italy: Is parents' sexual orientation associated with child health outcomes and parental dimensions? Journal of Developmental and Behavioral Pediatrics, 39(7), 555-563. doi:10.1097/DBP. 0000000000000583

Baiocco, R., Ioverno, S., Cerutti, R., Santamaria, F., Fontanesi, L., Lingiardi, V., ... Laghi, F. (2014). Suicidal ideation in Spanish and Italian lesbian and gay young adults: The role of internalized sexual stigma. Psicothema, 26(4), 490-496. doi:10.7334/psicothema2014.1

Baiocco, R., Nardelli, N., Pezzuti, L., \& Lingiardi, V. (2013). Attitudes of Italian heterosexual older adults towards lesbian and gay parenting. Sexuality Research and Social Policy, 10(4), 285-292. doi: 10.1007/s13178-013-0129-2

Baiocco, R., Pistella, J., Salvati, M., Ioverno, S., \& Lucidi, F. (2018a). Sexual prejudice in sport scale: A new measure. Journal of Homosexuality. Advance Online Publication, 1. doi:10.1080/00918369.2018. 1547560

Baiocco, R., Pistella, J., Salvati, M., Ioverno, S., \& Lucidi, F. (2018b). Sports as a risk environment: Homophobia and bullying in a sample of gay and heterosexual men. Journal of Gay \& Lesbian Mental Health, 22(4), 385-411. doi:10.1080/19359705.2018.1489325

Camodeca, M., Baiocco, R., \& Posa, O. (2018). Homophobic bullying and victimization among adolescents: The role of prejudice, moral disengagement, and sexual orientation. European Journal of Developmental Psychology, 16(5), 503-521. doi:10.1080/17405629.2018.1466699

Ioverno, S., Carone, N., Lingiardi, V., Nardelli, N., Pagone, P., Pistella, J., ... Baiocco, R. (2018). Assessing Prejudice toward two-father parenting and two-mother parenting: The beliefs on samesex parenting scale. Journal of Sex Research, 55(4-5), 654-665. doi:10.1080/00224499.2017.1348460

Lingiardi, V., Baiocco, R., \& Nardelli, N. (2012). Measure of internalized sexual stigma for lesbians and gay men: A new scale. Journal of Homosexuality, 59(8), 1191-1210. doi:10.1080/00918369.2012. 712850

Lingiardi, V., Nardelli, N., \& Drescher, J. (2015). New Italian lesbian, gay and bisexual psychotherapy guidelines: A review. International Review of Psychiatry, 27(5), 405-415. doi:10.3109/09540261.2015. 1064875

Lingiardi, V., Nardelli, N., Ioverno, S., Falanga, S., Di Chiacchio, C., Tanzilli, A., \& Baiocco, R. (2016). Homonegativity in Italy: Cultural issues, personality characteristics, and demographic correlates with negative attitudes toward lesbians and gay men. Sexuality Research and Social Policy, 13(2), 95-108. doi:10.1007/s13178-015-0197-6 
Meyer, I. (2003). Prejudice, social stress, and mental health in lesbian, gay, and bisexual populations: Conceptual issues and research evidence. Psychological Bulletin, 129(5), 674-697. doi:10.1037/00332909.129.5.674

Naal, H., Abboud, S., \& Mahmoud, H. (2019). Developing an LGBT-affirming healthcare provider directory in Lebanon. Journal of Gay \& Lesbian Mental Health, 23(1), 107-110. doi:10.1080/19359705. 2018.1538919

Pacilli, M. G., Taurino, A., Jost, J. T., \& van der Toorn, J. (2011). System justification, right-wing conservatism, and internalized homophobia: Gay and Lesbian attitudes toward same-sex parenting in Italy. Sex Roles, 65(7-8), 580-595. doi:10.1007/s11199-011-9969-5

Pistella, J., Salvati, M., Ioverno, S., Laghi, F., \& Baiocco, R. (2016). Coming-out to family members and internalized sexual stigma in bisexual, lesbian and gay people. Journal of Child and Family Studies, 25(12), 3694-3701. doi:10.1007/s10826-016-0528-0

Rosati, F., Pistella, J., Ioverno, S., \& Baiocco, R. (2018). Variabili relazionali e benessere psicologico in persone anziane gay, lesbiche, bisessuali e transgender: Una rassegna critica. Giornale Italiano di Psicologia, 45(3), 611-638. doi:10.1421/92816

Salvati, M., Pistella, J., Ioverno, S., Laghi, F., \& Baiocco, R. (2018). Coming out to siblings and internalized sexual stigma: The moderating role of gender in a sample of Italian participants. Journal of GLBT Family Studies, 14(5), 405-424. doi:10.1080/1550428X.2017.1369916

Roberto Baiocco, $\mathrm{PhD}$

Associate Professor of Developmental Psychology Sapienza University of Rome, Italy Psychologist and Family Therapist Director of the "Be as you Are" Clinical Research Center Via dei Marsi 78 (00185), Rome Italy (IT)

@ roberto.baiocco@uniroma1.it (D) http://orcid.org/0000-0002-6372-3762

Jessica Pistella, PhD

Research Assistant

Sapienza University of Rome, Italy

"Be as You Are" internal collaborator

Q2 jessica.pistella@uniroma1.it (D) http://orcid.org/0000-0002-4133-0503 